\title{
Cultural Characteristics and Value Connotation of Female Status-From Husband-Wife Intimacy Perspective in China
}

\author{
Helin Liu, Liyou Xiong \\ Department of Foreign Languages, Changsha University, Changsha, Hunan, China
}

\begin{abstract}
Wife-husband relationship is regarded as the most intimate relationship between two individuals. Researches show that a positive intimate couple relationship and the rise of female status can help maintain the harmonious marriage and family, thus promoting social harmony and stability. Husband-wife intimacy and female status can be well mirrored in regular conducts between them like sleeping ways, touching, spending leisure time together, making co-decision and sharing household chores etc. It is culture that affects and constructs husband-wife intimate relationship and female status. Hence, the exploration of cultural characteristics and value connotation behind is needed.
\end{abstract}

Keywords: intimacy between husband and wife, status of females, harmonious development

\section{Introduction}

An intimate relationship, an interpersonal relationship involving physical or emotional intimacy, makes up a social network to which human beings are strongly emotionally attached. As families constitute the cells of a society, a close family relationship becomes essential for the harmonious society, in which intimate couple relationship takes a key play. Marriage, the form of combination between genders, helps maintain social stability and promotes cooperation in different groups (Zhou \& Qin, 2009). However, marriage was in an unstable or even breakdown state in some European and American countries in 1960s, resulting in a rapid increase in the divorce rate and crime rate. Statistics showed that the chances of first marriage in the United States ending in divorce were about one in two. Bumpass (1990) considered that if the situation continued, 60 percent of marriages would end in divorce. Eitzen and Zinn (1997) stated that the U.S. divorce rate was the world's highest-more than triple the Japanese rate and at least double the divorce rates in other major industrial democracies except England. In America, some couples are indeed successful, but many people fall short of sustaining the intimacy required by their partner. This often results in a search for a new partner or partners who will provide the intimacy so intently craved. This is a major source of marital strain and helps account for the high divorce rate in contemporary America (Zinn, 2002).

Comparatively, Chinese traditional marriage is relatively stable, however, with globalization gradually affecting the way people think and act, traditional social values and ethics on marriage as well as people's outlook on life are being challenged. By making an analysis of regular conducts between husband and wife, this

Liu Helin, M.A., Associate Professor, Department of Foreign Languages, Changsha University.

Xiong Liyou, Ph.D., Professor, Department of Foreign Languages, Changsha University.

Correspondence concerning this article should be addressed to Room 506, Building 4, Sijimeijing (四季美景) Residential Quarter, Kaifu District, Changsha 410003, Hunan, China. 
paper intends to explore the female status as well as the hidden culture behind in China.

\section{Husband-Wife Intimacy and Female Status Reflected in Regular Conducts}

Intimacy usually implies relative equality, a kind of amicable and non-aggressive disposition to those with whom you have intimate relationship. Husband-wife intimacy reflects the degree of affection which means that the other is unique and irreplaceable. This kind of uniqueness thus becomes the cultural criterion for the construction of intimate couple relationship and the prerequisite for all the related matters. Nevertheless, in the real life, relationships between husband and wife seem not to be in an ideal situation when concern or love for the other may be more or less ignored. It is obvious that the lacking of love or emotion so greatly affects the intimacy between husband and wife that it is regarded as a kind of social tragedy. However, this situation is being changed. "In the last two decades, a new emphasis on relationships and sexuality has emerged to create an 'intimacy revolution'” (Whyte, 1990; see Zinn, 2002). As Giddens (2001) pointed out that intimacy was a matter of emotion exchange with others or even with oneself under an equal interpersonal context. It is truly to say that women have laid a foundation for widening the arena of intimacy for the innovation of modern emotional communication.

Accordingly, in recent years, some researches have been done to the strengthening of intimacy. Munck and Korotayev (2007) used five variables as indicators of husband-wife intimacy: husband-wife sleeping proximity, privacy in sleeping for husbands and wives, husband-wife eating arrangement, husband-wife spending leisure time together, and husband attending birth of his child. By referring to these variables, couple's sleeping ways, intimate touching, spending leisure time together, making co-decision and sharing household chores will be analyzed and the social and cultural connotation behind family discourse be revealed.

\section{Husbands and Wives' Sleeping Ways}

Psychologists believe that people display their genuine and frail nature in sleeping hours during which they will not intentionally fabricate their body language. The sleeping position between husband and wife can reflect their intimacy degree and female statues. Generally, a couple sleeps in a preferential or accustomed way. Any change of the habitual way of sleeping can mean some change of husband-wife relationship. After making a questionnaire of over 2,000 couples about their sleeping ways, relationship psychologist Corrine Sweet and the Travelodge Hotel Group summarized some sleeping manners to disclose husband-wife intimate relationship such as the Liberty, Spoons, the Romantic and Star-fish style. The Liberty-back to back but not touching - shows a couple feels connected whilst independent enough to sleep separately. Spoons or cuddling, a traditional sleeping way, often has the husband holding his wife inside as a protector, representing an intimate relationship as well as a sense of security of the female. However, the position may change with age when the female is spooning on the outside, indicating her dependence on or attachment to the male. Another similar way to show the woman's attachment to her man is the Romantic, where the man lies on his back with the woman's head and arm on his chest, manifesting his strong sense of self-confidence and the role of protector if he puts his arm around her at the same time. This intimate pose is much favored in a new relationship or after love making. Nevertheless, there may be also an implication of the wife's self-decision mind if she has her head on her husband's chest with an extension of her body. Females lying in star-fish position often take the lead in the family while the male is happy to oblige, another way of sleeping to indicate the intimate relationship. 
It is obvious that intimate relationship and female status can be reflected in their sleeping habits. Indeed, sleeping together contributes to more happiness and intimacy, as many women admit that they feel safer and more dependable with husband sleeping with. However, there are still couples who choose to sleep apart to vindicate their privacy and independence. Even though some couples admit to sleeping separately from their partner in the quest for a good night's sleep, it can be viewed as a behavior to escape family responsibility, for marriage needs sacrifice and share of happiness and sorrows. Experts believe that a lasting marriage is enhanced when couples sleep together and are content with their relationship. Sleeping separately is self-indulgent and prone to an emotional distance. The longer a couple sleeps apart, the less intimate their relationship will grow, and the more possible their marriage goes to an end.

\section{Intimate Touching Between Husband and Wife}

Touching, like physical closeness, may be considered as an expression of affection, support, or sexual attraction. Knapp and Hall (1997, p. 303) reported "inconsistent" findings on "which sex touches the other more, overall”. When husband-wife relationship becomes more intimate and committed, gender differences in the initiation of touch between partners appear less evident. Yet even in such relationships, Knapp and Hall contended that "observers seem to perceive the initiator [of touch] as the person with greater power" (Samovar \& Porter, 2007). These findings have important implications for both women and men. Just as other communication behaviors, touching is also constrained by culture. In some cultures, couples or lovers can kiss or embrace in public places, while in other cultures it is forbidden. In ancient time of China when males were superior to females, Zhang chang (张敞: ?BC-48BC), a Metropolitan Governor (jingzhaoyin/京兆尹) in the West Han Dynasty (206BC-25AD) penciled eyebrows for his wife every day. Notwithstanding, an intimate behavior between the couple, he was disposed from his post for this so-called disturbance of social order.

It is vital to understand or comprehend the meaning of touching. In Judith Hall's (1984) extensive review of students of differences in decoding nonverbal messages, women were found to be significantly better decoders of nonverbal cues than were men (Samovar \& Porter, 2007). Lasswell and Robozinc (1980, p. 190) depicted "touching" as "the most natural human behavior", but meanwhile, they also found that touching was avoided by many couples who didn't think it pleasant. In terms of sex, a wife dislikes touching when she thinks a touching from her husband is nothing but sexual demand; similarly, she will also hesitate to touch her husband for fear that he may view it as a signal of sexual desire. In her concept of oppression, Nancy Henley (1973, 1977) supposed that women, and others who have less power, must learn to "read" the nonverbal messages of those who have authority over them, not to mention those who are oppressed. Henley claimed that this could explain why women and other subject people had stronger interpersonal sensitivity. It appears impossible to provide one definitive explanation for women's greater facility with decoding nonverbal messages. Basically, all of the explanations offered to date fall into two categories: (1) theorists who relate women's greater nonverbal decoding skills to needs that arise out of their subordinate status and (2) theorists who attribute women's nonverbal skills to their greater tendency toward affiliation with others. However, as Hall contends:

it is...difficult to disentangle these two basic explanation—-dominance and affiliation—because of the possibility that women's lower status reduces their ability to challenge or threaten anyone, which in turn enables or requires them to act warm and nice. (1984, p. 84; see Samovar \& Porter, 2007, p. 277) 


\section{Husband-Wife Spending Leisure Time Together}

From a social constructionist perspective, time and intimacy are shared co-created experiences (Daly, 1996; Weingarten, 1991). In 20 years of study and collection of family strengths data on more than 20,000 families in 27 different countries, Stinnett and DeFrain, (1985; 1992) proposed that six major qualities are common in the lives of happy and harmonious families, which include commitment, appreciation and affection, positive communication, time together, spiritual well-being, and the ability to cope with stress and crisis. These qualities will undoubtedly increase intimacy between husband and wife. However, intimacy cannot be established only by marriage based on love. In China before the year of 1949, there existed a kind of "child bride" marriage where a little boy and a girl were arranged into a couple without love and intimate feelings may gradually be developed after living or spending time together. Contrary to this, the Mosuo people (摩梭人) in Naxi Nationality (纳西族) of Yunan Province (云南省) in southwest China have the custom of male-leaving marriage, constraining the development of intimate relationship after marriage. Thus, some scholars think that the intimate-nonintimate continuum should not, in other words, be viewed as an analogue of marriage dichotomy based on love (Munck \& Korotayev, 2007).

Under the context of entertainment, daily consumption and spending leisure time together, men behave more positively in that they expect to meet their own need of independence, freedom, dominance and self-respect at the same time to meet their wives' need or desire for intimate relationship. In other words, most males voluntarily cater to their mates' expectation of spending leisure time together without sacrificing their own needs (Su \& Gao, 2004). As a matter of fact, the impact caused by the lacking of husband-wife staying together or spending time together is immense. Nowadays, the decrease of husband-wife intimacy, the extramarital affairs or even divorce in China are often caused by the husband's leaving the countryside to work in big cities, or going abroad for business or study for a long time, with their wives left at home isolated whose emotional and sexual needs can hardly be met. However, for many families, with the strengthening of spiritual needs and family responsibility, there is an increase in husband-wife spending leisure time together in terms of shopping, travelling, sporting or visiting friends and relatives, which may be associated with higher marital satisfaction (Amato et al., 2007). It is evident that shared time experiences are central to relationship satisfaction and encourages couples to construct their own rhythms of intimacy (Reynolds, 2015).

\section{Husbands and Wives' Co-decision and Sharing Household Chores}

Female status is generally classified into social status and family status. In China, researchers usually take the female's decision-making right of family affairs as one of the main variables to measure her family status (Pan, 1987; Sha, 1995; Xu, 2005; Hao \& Zhang, 2014). A survey shows that $42 \%$ females have the economic dominance over daily necessities; however, they are still in a subordinate position in deciding crucial family affairs such as housing, business planning and children's education. More than $60 \%$ Chinese wives can share family real power and decision making, among which urban women account for $71 \%$ while rural women $56 \%$, yet the proportion is far lower than that in America and Sweden with $82 \%$ and $93 \%$ respectively (Tan, 2006). Early in 1960s, studies showed that right is what really matters in the family structure because it embodies one's potential ability over the other's behaviors (Blood, Robert, \& Wolfe, 1960). Different working positions, different rights and obligation and different expectations can all lead to the inequality of housework distribution, thus producing tension and affecting communication between husband and wife. 2015 White Paper on Gender Equality and Women's Development in China pointed out that over the past 20 years, a marked improvement 
has been seen in gender equality in marriages and families. The recent survey of Chinese women's social status shows that it has become the norm for husbands and wives to make family decisions jointly, and that more than $70 \%$ of women have taken part in making major family decisions. More and more women can share family resources on an equal basis with men, and the concept of men and women sharing housework is now accepted, with the housework time gap between men and women shortened from 150 minutes 10 years ago to 74 minutes now. In some sense, this demonstrates that the higher degree the social modernization is in, the higher social status the women have.

As a multifaceted, dynamic and complex interactive process, family power and status between men and women is built upon interpersonal and sign communication of love and respect and is hard to measure because of its vagueness, indirectness and potentiality ( $\mathrm{Wu}, 2008)$. So far, the labor division mode of "man as breadwinner and woman homemaker" in Chinese society has not been fundamentally changed. The majority of wives are shouldering more household chores, even if they have the same working hours and payments as their men. Therefore, some researchers regard females' shouldering more housework as an index to their lower family status (Xu, 2005). Indeed, housework construct more than series of simple instrumental tasks; mutual communication, respect and attachment between husband and wife can be achieved through household chores, which further increases their satisfaction with their marriage and thus promotes intimacy between them.

\section{Factors for Improving Female Status and Husband-Wife Intimate Relationship}

\section{Culture Constructing Female Status and Affecting Intimacy}

The purpose of linguistic philosophy tends to reveal "the world between human beings" by means of linguistic analysis. According to historical materialism, culture belongs to the superstructure with the social ideology as its core. Studies show that culture is a kind of frozen inter-personal communication while communication is the fluid culture. Therefore, cultural factors (social, psychological, natural, spatial etc.) construct female statues and affect intimate relationship between husband and wife.

Whether gender differentiation and sexual orientation are determined by physiological nature or constructed by culture has long been an important issue in gender studies. By providing quantities of evidence, anthropologists proved that gender relations are constructed by culture rather than determined by its biological nature. In the book of Oppressive Dichotomies: The Nature /Culture Debate, Brown and Jordanova (1981) noted that for centuries in the western ideological field there was a dichotomy that females were attributed to nature while males to culture, indicating females were in an inferior social position. In ancient Chinese culture, there was also a series of binary opposite factors, like Yang ( $\beta$ 月) and Yin ( $(\beta$ ) $)$, Heaven (天) and Earth (地), Men (乾) and Women (坤), Monarch (君) and Subjects (臣) in a hierarchical. Marx and Engels once said, “the essence of man is no abstraction inherent in each single individual. In reality, it is the ensemble of the social relations” (Engels, 2010). This tells us that males and females are not only possessed of biological sex, but exist in certain social relations. Thus, the nature of men and women should be identified by the "ensemble of the social relations" in addition to their biological characteristics. Feminists also argued that physiological formation cannot be a fix determinant, since culture almost makes gender differences in the myriads of changes. In so far as gender goes, both women and men are products of social relations; the change of social relations can alter the categories of "women" and "men". Nevertheless, in terms of macro social structure, women are in an overall inferior or secondary status in the man-oriented culture (Luo \& Liu, 2000). 
In the earlier classics I Changing or Book of Changes ( 《周易》), an ancient divination text, there were sumptuous discussions on gender relations as well. According to the record of Chinese Classics, in the primitive time, people originally had a commonly-recognized First Grandmother, or the earliest maternal ancestor such as Jiandi (简狄) in the Shang tribe and Jiangyuan (姜原) in the clan of Zhou of primitive time. Zhuangzi Daozhi (《庄子.盗跖》) depicted that “At the time of Shenlong (神农: the mythical character, the patron of agriculture) ... people knew their mother, but not father." While, in Spring and Autumn-Tabled a Gentleman. (《吕氏春秋・持君览》), it was written that “At the time of immemorial, people clustered, knowing their mother but not their father." All these exemplified that female once dominated the society in Chinese history. However, with the development of social productivity, men took a lead in the production and gained a dominating position in the clan. Thus, a cultural feature of male-respected and female-humbled modal in the patriarchal society (5,000-6,000 years ago) appeared, which not only normalized gender characteristics but also conditioned how different sex used verbal and non-verbal language. Females once dominating the clan were pressed to the bottom of the society by various compulsory means from political, economical and ethical respects (Liu, 2011). Though ancient China experienced different productive features, economic forms, tribal system and political system in different dynasties, yet, women were invariably in an oppressed and dominated position over the history of more than 2,000 years of federalism (246BC-1911AD) (He, 2004).

It is the federal ethic codes in ancient China that chained them to a powerless state. Book of Rites (《礼记》) illustrates that a woman should obey her father before marriage, and her husband during married life and her sons in widowhood (Note: which is also called "Three Obediences" of ancient Chinese women), which indicated that the existence of females was the premise of father-son relationship, therefore, females were delimited within a circle by certain principles in the paternal society and dare not go beyond the limit. The Three Cardinal Guides (“三纲”: ruler guides subject, father guides son and husband guides wife) and The Five Constant Virtues (“五常”: benevolence, righteousness, propriety, knowledge and sincerity) were typical examples of feudal ethical codes to confine females in ancient China. Even in ancient Chinese poetry, women images were depicted as objects with words like as pretty as flower and jade, a beauty with flesh of ice and bones of jade. American scholar Ann du Cille (1994) noted in her seminal essay "Dyes and Dolls: Multicultural Barbie and the Merchandising of Difference" that even Barbie, a simple fabricated plastic doll, is loaded with specific function of ideology. Observed from the perspective of gender, what Barbie transmitted with her mature body of perfect curves and charming breasts is just sex rather than maternity. From a patriarchy view, Doll Barbie is nothing but an icon of sexualized, commodified femininity.

Admittedly, we do not agree with the distinction of superiority and inferiority between genders, however, gender position differences still exist in different countries, region or people's interactions. Stereotypes of female subordination are also rooted in some minds, which will inevitably have negative impact on the development of husband-wife intimacy.

\section{Globalization Reconstructing Female Status and Affecting Intimacy}

Nowadays, the impact of globalization is over every corner of the world. The globalization of economy has sped up social development. People's life quality has been improved with higher pay and good education than before, thus exerting a positive impact on the rise of female status. According to the report by UNIFEM in 2000 , economy is relatively stable in regions where women are in progress, and remain stagnant when women are restricted. Therefore, a government should have a strong investment in health, education and other services 
which directly affects women's benefits to promote economic growth. Women are quick to lose their autonomy in the family without good education and disposable income.

Under the current situation of economic globalization, many things that are crucial to females are promised: employment, prosperity, right and justice, working conditions and pay packages, and of course, an increase in the status of women (Jaggar, 2001). With regular wage work, "women gain greater personal autonomy and independence...[They] gain more control over budgeting and other domestic decisions and greater leverage in requesting help from men in domestic chores” (Sassen, 1996). More chances of employment enable some women to gain success in their field. The improvement of their financial situation is always accompanied by relative promotion of their power and status both in family and society. On the other hand, from a critical point of view, economic globalization has also brought some negative impact on women. A new international order brought by globalization has given rise to new unfair distribution between power, wealth and opportunities in the new condition, penetrating into the national level, social level or even family level. The same work as men but without the same pay, together with sexual harassment still displays female's lower status. In addition, more chances of employment enable women to be far away from their families, thereby, reducing the intimate degree of husband- wife relationship.

Cultural globalization, the transmission of ideas, meanings and values around the world in such a way as to extend and intensify social relations (Paul James, 2006), is essentially a continuum of challenge to modernity, though it will not be a threat to the social system. Culturally, it is a challenge to the cultural diversity, as there appeared multiple choices in the belief, values and social patterns. As cited above, America is a nation with highest rate of divorce; however, it is also a country with the highest rate of marriage. The reason for this lies in the American marriage political and cultural values. American constitution guarantees personal right for the happiness. Americans care much about their family happiness, however, when they feel the marriage unhappy and unsatisfactory, they tend to be more on their own happiness and self-feeling, divorce will be the best choice (Su, 2004). On the contrary, Chinese people consider marriage as the most important thing in the life. Even they don't feel happy about the marriage, they would choose to keep the situation rather than to divorce-a kind of cultural value of collectivism to maintain public image or face. However, multi-cultures have also exerted certain impact on traditional Chinese marriage. Some extramarital affairs like man's having a mistress, woman's having a gigolo, or even cyber love have become complementary forms outside the marriage. And the "temporary husband and wife" among the migrant workers have aroused the attention of the NPC and CPPCC. It is evident that value orientation behind these phenomena has shaken or affected, to a certain extent, the female status and husband-wife intimacy.

\section{Summary and Discussion}

The international criteria of marriage quality include sense of happiness, satisfaction with marriage, flexibility of marital relationship, difficulties in marital interaction, satisfaction with marital sex, etc. Therefore, it should be realized that gender equality is an important condition and feature of harmonious family and society. In view of gender equality we suggest:

(1) Deepening the understanding of government at different levels and expanding discourse power of women's liberation

A series of introduction of documents such as Beijing Platform for Action (1995), The Law of People's Republic China on the Protection of Rights and Interests of Women (revised, 2005), The Program for the 
Development of Chinese Women: 2011-2020 (2011), Anti-domestic Violence Law (2015), and Gender Equality and Women's Development in China (white paper, 2015), together with the publication of The Action Agenda and Beijing Declaration etc., have made it clear that Chinese government has achieved fruitful results in promoting gender equality and women's development. The discourse of Chinese women's liberation has become the political discourse of the country in a real sense. At the same time, we must realize there are still phenomena of insufficient recognition of female status and right discourse. According to an investigation, except All-China Women's Federation (ACWF), only 44.8\% of the top decision-makers recognize the significance of the basic state policy of gender equality (Tan, 2006). Therefore, it is important and urgent to raise the awareness of gender equality among the governmental law-makers and decision-makers at different levels.

Another important measure to expand women's power of discourse is to increase the number of females in their participation in the administration and discussion of state affairs. Chen Zhili (陈至立), the former Chairman of ACWF, stated in 2013 that it was effective to rationally allocate female proportion in decision-making level. In addition to the political field, there should be a ratio of female middle-level managers in enterprise boards, associations and public institutions. According to the statistic data of the implementation of The Program for the Development of Chinese Women (2011-2020) in 2014, there was a relative decrease in the proportion of female cadres in the leadership at all levels of government compared to 2013. Therefore, it is of great urgency to expand women's right to speak by increasing the proportion of female leaders at all levels.

(2) Creating condition for social development and promoting women's economic status inside the family

According to Karl Marx, the development of a society can be measured by women's social status, and the key to domestic gender equality and intimacy is to promote women's economic status. Hence, we should pay close attention to the living condition of women, especially those living in under-developed rural areas, and vulnerable female groups in urban and rural areas. And it is also necessary to narrow the gap of resource distribution between men and women, to provide equal education and training chance for women in the countryside and to optimize the pension insurance system in rural areas so as to change women's disadvantage in resources and promote their status in the family.

The Law on the Protection of Rights and Interests of Women should be further implemented to ensure the equal rights of women in education, employment and family property allocation. Whether women have the equal right of inheritance and family property can be viewed as an essential criterion for gender equality, an important representation of female status in a family and a physical basis for the establishment of husband-wife intimacy (Hao \& Zhang, 2014). With the two-child policy carried out in China, women are shouldering more family and social responsibilities. Hence, there should be more concern for their health, for their social and family status.

(3) Advocating advanced gender culture and improving the harmonious relationship between husbands and wives

Researches show that traditional cultural concept is the main obstacle of gender equality, so it should be replaced by new culture. In order to find the possible solution to gender equality and harmony inside the family, firstly we should form advanced gender culture, optimize the social environment for female development, and advocate diverse and balanced gender division of labor. And we should change the traditional interactive mode and custom of marriage, with husbands the superior and wives the inferior, and set up the new custom of gender equality and marital harmony. Secondly, the concept of gender equality should be advocated in the 
family, and the independent, democratic and harmonious values should also be formed. Lastly, we should carry the values of equality and justice through the improvement of female status.

With the present world being a "global village”, the development of China can't be separated from the development of the world, just like vise verse. As is said in the preface to Sexual Politics, a theoretical breakthrough of social sciences in China should be based on the common wealth of human being about social change and development. Chinese social theorists should participate in the joint knowledge accumulation of sociology in the world, follow the comprehensive trend of sociology in foreign countries, and grasp the frontier problems in sociology in the world. Women's liberation movement in China has made remarkable achievements since the May 4th Movement, but in order to build a harmonious society, it is still a top priority to promote the comprehensive development of human being, to improve women's status in politics, economy and culture, and blend in with world trend of development.

\section{References}

Amato, P., Booth, A., Johnson, D., \& Rogers, S. (2007). Alone together: How marriage in America is changing. Cambridge, MA: Harvard University Press.

Blood, R., \& Wolfe, D. (1961). Husbands and wives: The dynamics of married living. American Journal of Sociology, (1), 108.

Brown, P., \& Jordanova, L. (1981). Oppressive dichotomies: The nature/culture debate. In Cambridge Women's Studies Group (Ed.), Women in society: Interdisciplinary essays (pp. 224-241). London: Virago.

Chen, Z. L. (陈至立). (2013). Promote women's leadership, and the world will be better. Collection of Women's Studies, (4), 5-7.

Eitzen, D. S., \& Zinn, M. B. (1997). Social problems (7th ed.). Boston, USA: Allen \& Bacon.

Giddens, A. (2001). The transformation of intimacy: Sexuality, love and eroticism in modern society. (Chen, Y. G. \& Wang, M. A. Trans.). Beijing: Publishing House of Chinese Social Science.

Gray, M. M., Kittilson, M. C., \& Sandholtz, W. (2006). Women and globalization: A study of 180 countries, 1975-2000. International Organization.

Hao, J., \& Zhang, W. (郝佳、张伟). (2014). The construction and application of the cognitive model for women' s legal rights and interests-A study on the countermeasures based on the data of Shanxi Province in the 3rd survey for women's social status. Journal of Henan University of Economics and Law, (3), 88-96.

He, Y. B. et al. (何云波等). (2004). Cross the cultural wall: Contemporary world culture and comparative literature. Changsha: Hunan People’s Publishing House, 232. Retrieved from http://plato.stanford.edu/entries/feminism-globalization/

Jaggar, A. (2001). Is globalization good for women? Comparative Literature, 53(4), 298-314.

James, P. (2006). Globalism, nationalism, tribalism. London: Sage Publications.

Liu, H. L. (刘和林). (2011). On power relations and gender differences in nonverbal communication from cross-cultural perspective. Foreign Languages and Literature, (1), 93-96.

Luo, G., \& Liu, X.Y. (罗钢、刘象愚). (2000). Cultural studies: A reader. Beijing: China Social Sciences Press.

Munck, V. C., \& Korotayev, A. V. (2007). Wife-husband intimacy and female status in cross-cultural perspective. Cross-Cultural Research, 4(4), 309, 331-332.

Reynolds, C., \& Martin, C. K. (2015). Gender and the construction of intimacy among committed couples with children. Family Process, (54), 293-307.

Samovar, L. A., \& Porter, R. E. (2007). Intercultural communication: A Reader (10th ed.). Shanghai: Shanghai Foreign Language Education Press.

Sassen, S. (1996). Toward a feminist analytics of the global economy. Indiana Journal of Global Legal Studies, 4(1), 7-42.

Su, Y. J., \& Gao, P. (苏彦捷、高鹏). (2005). On behavior and attributions of conflict among partners of intimate relationships. Journal of Peking University (Philosophy and Social Sciences), (4), 122-125.

Sun, Z. J. (孙智骏). (2004). Studies on divorce in the 20th century U.S. [D]. East China Normal University.

Tan, L. et al. (谭琳等). (2006). Evaluation report on gender equality and women development in China, 1995-2005. Beijing: Social Science of Academic Press.

Wang, M. A. (汪民安). (2007). Key words in cultural studies. Nanjing: Jiangsu People’s Publishing Press. 
Wolcott, I. (1999). Strong families and satisfying marriage. Family Matters, Winter, Issue 53.

Wu, Y. M. (吴越民). (2008). Deconstructing on feminist media criticism in the context of cross-culture. Journal of Zhejiang University, (4), 109-116.

Xu, A. Q. (徐安琪). (2005). Gender studies in social and cultural transition. Shanghai: Shanghai Academy of Social Sciences Press.

Zhou, D. M., \& Qin, H. Z. (周大鸣、秦红增). (2009). A survey of cultural anthropology. Guangzhou: Zhongshan University Press.

Zinn, M. B. (2002). Diversity in families (6th ed.). Boston, MA: Allyn \& Bacon. 